\title{
Advantages of Using Ultrasound in Regional Anesthesia for a Super-Super Obese Patient
}

\author{
Woo Jae Yim, Kyoung Sub Yoon, Jeong In Hong, Sang Yoong Park, So Ron Choi, Jong Hwan Lee \\ Department of Anesthesiology and Pain Medicine, Dong-A University College of Medicine, Busan, Korea
}

In this case report, we describe the use of ultrasound in the administration regional anesthesia for a super-super obese patient. A 23-year-old female patient (height $167.2 \mathrm{~cm}$, weight $191.5 \mathrm{~kg}$, body mass index $68.6 \mathrm{~kg} / \mathrm{m}^{2}$ ) was admitted to the hospital for surgical repair of an anterior talofibular ligament rupture. We used ultrasound to help facilitate the administration of regional anesthesia. In the sagittal view of the lumbar spine, (with the patient in a sitting position) we were able to identify the border between the sacrum and the lumbar vertebral; in the transverse view, we were able to identify the transverse process, posterior dura, vertebral body, and the distance from the skin to the posterior dura. After skin marking, regional anesthesia was successfully performed. Based on this case study, we suggest that ultrasound can be very useful in regional anesthesia for severely obese patients.

Key Words: Anesthesia, Obesity, Ultrasonography

As obesity rates continue to increase, clinicians face more challenges in delivering standard medical care. Body mass index (BMI), which is often used to diagnosed overweight and obese patients, now classifies a BMI $\geq 50 \mathrm{~kg} / \mathrm{m}^{2}$ and a BMI $\geq$ $60 \mathrm{~kg} / \mathrm{m}^{2}$ as super-obesity and super-super obesity, respectively. ${ }^{1}$ When it comes to administering anesthesia to super-super obese patients, there are many factors to consider. During general anesthesia, intubation can be difficult due to an obstructive airway or a limitation of mask ventilation. Additionally, there is an associated risk of apnea and dyspnea occurring in the recovery room after surgery. ${ }^{2}$ Therefore, surgery in such patients is often performed under regional anesthesia.

In this report, we describe the case of a super-super obese patient who underwent regional anesthesia that was guided by ultrasound, which successfully helped determine the correct insertion point prior to spinal needle insertion.

\footnotetext{
Corresponding Author: Sang Yoong Park, Department of Anesthesiology and Pain Medicine, Dong-A University College of Medicine, 26, Daesingongwon-ro, Seo-gu, Busan 49201, Korea

Tel: +82-51-240-5390 Fax: +82-51-247-7819 E-mail: parksy@dau.ac.kr

\section{(c) (1) (2)}

Articles published in Kosin Medical Journal are open-access, distributed under the terms of the Creative Commons Attribution Non-Commercial License (http://creativecommons.org/licenses/by-nc/4.0/) which permits unrestricted non-commercial use, distribution, and reproduction in any medium, provided the original work is properly cited. 


\section{CASE}

A 23-year-old female patient presented with an anterior talofibular ligament rupture following a motor vehicle accident and was admitted for a surgical repair. The patient had a history of several surgeries at the same site, performed under local anesthesia. She also had a medical history of super-super obesity (height $167.2 \mathrm{~cm}$, weight 191.5 $\mathrm{kg}$, BMI $68.6 \mathrm{~kg} / \mathrm{m}^{2}$ ), insomnia, and obstructive sleep apnea. Regional anesthesia was used per the patient's request and to avoid the risk of complications from general anesthesia.

Initial vital signs showed a blood pressure of 132/84 mmHg, a heart rate of 85 beats/min, a respiratory rate of $20 / \mathrm{min}$, and an oxygen saturation of $97 \%$ in room air. Arterial blood gas showed $\mathrm{pH}$ 7.421, $\mathrm{PCO}_{2} 40.4 \mathrm{mmHg}$ and $\mathrm{PO}_{2} 93 \mathrm{mmHg}$.
Ultrasound was used to find the correct spinal needle insertion point. No medication was given for this procedure. Regional anesthesia was performed with the patient in a sitting position. Anatomical landmarks, such as the spinous processes, were not palpable by hand; therefore, the vertebral level could not be confirmed through palpation alone. Using ultrasonography (CX50, PHILIPS, USA), a probe (C5-1 Pure Wave curved array, PHILIPS, USA) was placed longitudinally on the lumbar vertebra, and the sacrum could be seen as a hyperechoic line. The lumbar vertebral level, as well as the vertebral body and spinous process, were confirmed by moving the probe cephalad up the spine. Skin markings were made to identify the 3rd, 4th, and 5th lumbar levels; the probe was then transversely rotated to identify the thickness of fat tissue, transverse process, posterior dura,

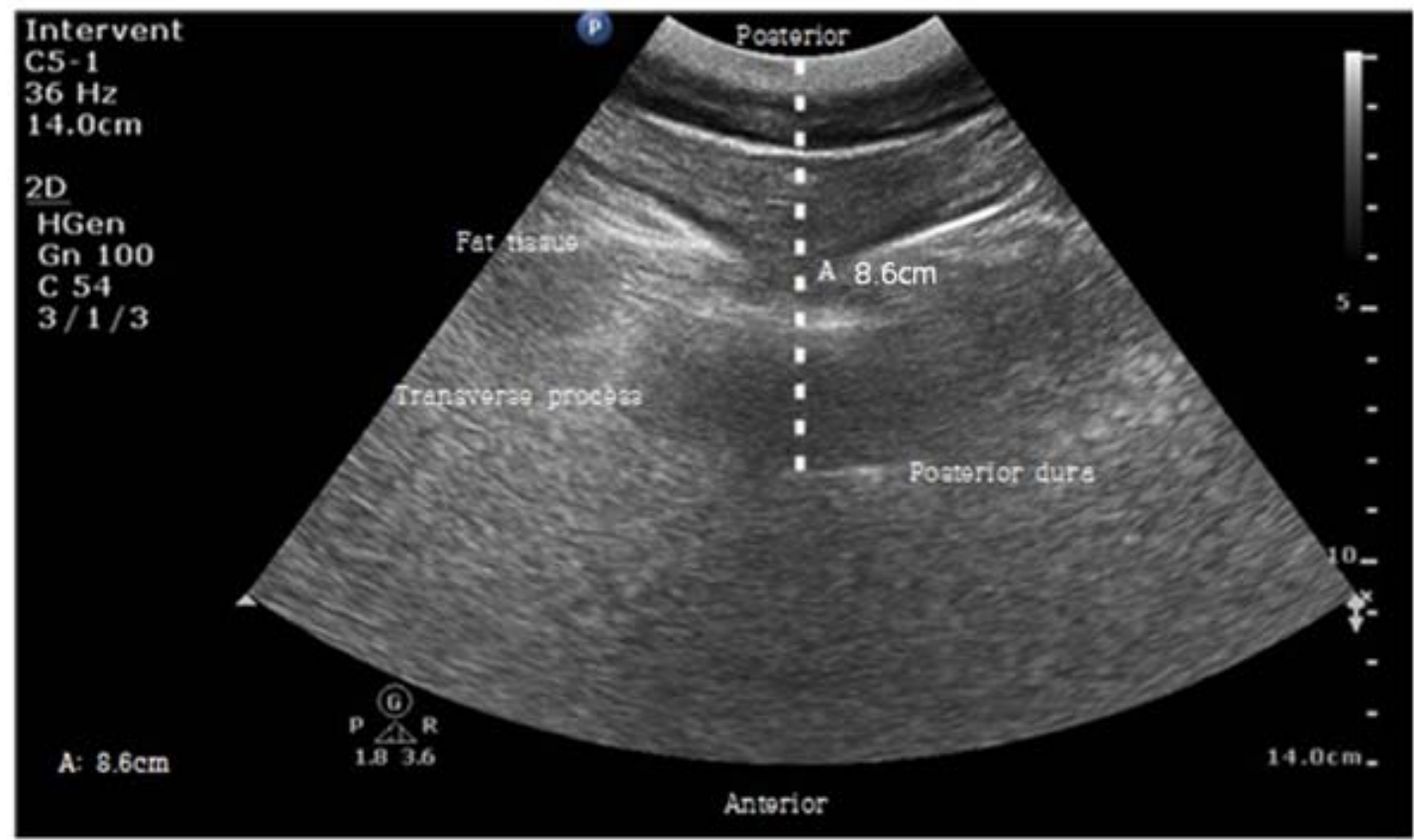

Fig. 1. Transverse view of the lumbar spine at the L4-L5 level. 
and vertebral body (Fig. 1). Based on the ultrasound image, the distance from the skin to the posterior dura was $8.6 \mathrm{~cm}$, and a $22 \mathrm{G} 100-\mathrm{mm}$ needle (Uniever, Unisis Corp., Tokyo Japan) was used. Needle insertion was successfully achieved on the first attempt. However, CSF flow was not confirmed after inserting the spinal needle to the end; it was confirmed only after pushing the needle vertically and compressing the surrounding tissue. Thus, 10 mg of $0.5 \%$ heavy bupivacaine was injected while maintaining the compressed state. A temperature discrimination test confirmed the extension of sensory blockade, which was found to be at thoracic level 6. Vital signs at this time showed a blood pressure of $121 / 70 \mathrm{mmHg}$, a heart rate of 89 beats/min, a respiratory rate of $20 / \mathrm{min}$, and an oxygen saturation of 95\% in room air. Arterial blood gas showed $\mathrm{pH} 7.446, \mathrm{PCO}_{2} 38.1 \mathrm{mmHg}$ and $\mathrm{PO}_{2}$ $84.7 \mathrm{mmHg}$. The patient was placed in a semiFowler position and received continuous oxygen, $5 \mathrm{~L} / \mathrm{min}$, through a face mask. Per the patient's request, no sedatives were administered. The duration of the surgery was 85 minutes, and there were no anesthetic complications.

\section{DISCUSSION}

The growing rate of severely obese patients is no longer an exception in South Korea. As this population grows, anesthesiologists may encounter such patients who require anesthesia. This case study found that using ultrasound to administer regional anesthesia was beneficial in a super-super obese patient.

The perioperative care of an obese patient is a challenging task. Airway management should be carefully considered, particularly in cases where intubation is difficult. Obesity is associated with an increased perioperative risk of respiratory complications, cardiopulmonary dysfunction, acid aspiration, and mortality. ${ }^{2,3}$ Approximately 5\% of morbidly obese patients have obstructive sleep apnea (OSA). As the pharyngeal airway collapses, apnea develops, and pharyngeal patency is maintained by the muscles that prevent upper airway obstruction. During sleep, however, the tone of these muscles decreases, causing apnea. ${ }^{2}$ For this reason, complications such as apnea and dyspnea should be monitored more closely in obese patients during perioperative care.

In consideration of these risks, regional anesthesia may be preferred over general anesthesia, but OSA in obese patients should be closely monitored during regional anesthesia, nonetheless. In this case study, the patient had been moved from the supine position, which is typically used in these types of surgical repairs, to the semi-Fowler position. It is found that, the semi-Fowler position unloads the diaphragm of the intra-abdominal contents. ${ }^{4,5}$ Therefore, morbidly obese patients have increased pulmonary compliance and functional residual capacity while in the semi-Fowler position.

Severe obesity makes it difficult to determine the distance from the skin to the posterior dura, ${ }^{6}$ 
which makes it difficult to perform specific anesthetic procedures. Recent studies have shown that the use of ultrasound before regional anesthesia in obese patients facilitates these procedures. ${ }^{7,8}$ In the case of regional anesthesia, anatomical landmarks are usually identified to locate the correct needle insertion point; however, it is often difficult to find these anatomical landmarks in obese patients due to the thick layer of adipose tissue. Therefore, ultrasound is useful to find these anatomical landmarks.

Peripheral nerve blocks, such as the sciatic nerve block or femoral nerve block, were also considered at the beginning, but the layer of adipose tissue above the vertebra was very thin.

Studies have shown that regional anesthesia has a high nerve-block failure rate in obese patients. ${ }^{2,9}$ Surface landmarks are frequently unclear in obese patients, making it difficult to perform regional anesthesia. However, it is helpful to identify the correct spinal needle insertion point using ultrasound. The use of ultrasound imaging with regional anesthesia in obese patients can be helpful in determining the correct vertebral level in the lumbar spine, placing midline skin markings, and measuring dura mater depth. ${ }^{6,8}$ Sprung et al. ${ }^{6}$ found that the accuracy in identifying landmarks was the most important independent variable in determining the level of difficulty in administering regional anesthesia. The curvilinear probe that was used in this study may be an appropriate choice for other obese patients, since it uses a lower frequency allowing a deep penetration, which helps distinguish the deeply located dura. ${ }^{10}$

Sahin et al. ${ }^{11}$ found that there was a difference between the length measured by the ultrasound and the actual needle depth. It was determined that the distance measured with ultrasound was less than the actual needle depth due to subcutaneous tissue compression by the ultrasound probe in obese patients. In this case, the spinal needle insertion was not measured in real-time. To simultaneously insert the needle while checking the dura with the probe, the needle insertion must be performed at a trajectory. However, the longest spinal needle available in the hospital was $100 \mathrm{~mm}$ in length; the CSF flow was only confirmed after pushing the needle vertically and compressing the surrounding tissue, which presented a limitation of this case. The difference between the actual needle length and the distance from the skin to the posterior dura (measured by ultrasonography), will be investigated in our next study. We generally use a $24 \mathrm{G}$ or $25 \mathrm{G}$ spinal needle for these procedures; however, narrow gauge spinal needles are flexible and are likely to kink as a result of the large distance from the skin to the dura in an obese patient. Therefore, we used a $22 \mathrm{G}$ spinal needle, despite the increased risk of post-dural puncture headache. ${ }^{12}$

In general cases, we typically use a specific needle guide (Infiniti, CIVCO, Kalona, IA, USA) to help reduce the nerve-block failure rate of regional anesthesia. The needle guide allows full control of the needle in real-time. However, in our case, there was a limitation in using the needle guide: the distance from the skin to the dura was large, 
and the needle would have to be inserted at an angle. If the distance between skin and dura was not so large, it would have been helpful. However, due to the patient's body habitus, the needle needed to be inserted vertically.

In conclusion, the use of ultrasound is helpful in determining the spinal needle insertion point before administering regional anesthesia. The use of ultrasound may be necessary to perform regional anesthesia in severely obese patients.

\section{REFERENCES}

1. Mayson EE, Doherty C, Maher JW, Scott DH, Rodriquez EM, Blommers TJ. Super obesity and gastric reduction procedures. Gastroenterol Clin North Am 1987;16:495-502.

2. Adams JP, Murphy PG. Obesity in anaesthesia and intensive care. Br J Anaesth 2000;85:91-108.

3. Shenkman Z, Shir Y, Brodsky JB. Perioperative management of the obese patient. Br J Anaesth 1993;70:349-59.

4. Brodsky JB. Perioperative management of the obese patient. Conferencias Magistrales 2008;31:S85-9.

5. Brodsky JB. Positioning the morbidly obese patient for anesthesia. Obes Surg 2002;12:751-8.

6. Sprung J, Bourke DL, Grass J, Hammel J, Mascha E, Thomas P, et al. Predicting the difficult neurax- ial block: a prospective study. Anesth Analg 1999;89:384-9.

7. Chin KJ, Perlas A, Chan V, Brown-Shreves D, Koshkin A, Vaishnav V. Ultrasound imaging facilitates spinal anesthesia in adults with difficult surface anatomic landmarks. Anesthesiology 2011; 115:94-101.

8. Grau T, Leipold RW, Conradi R, Martin E, Motsch J. Ultrasound imaging facilitates localization of the epidural space during combined spinal and epidural anesthesia. Reg Anesth Pain Med 2001;26:64-7.

9. Cotter JT, Nielsen KC, Guller U, Steele SM, Klein SM, Greengrass RA, et al. Increased body mass index and ASA physical status IV are risk factors for block failure in ambulatory surgery -an analysis of 9,342 blocks. Can J Anaesth 2004;51:810-6.

10. Carty S, Nicholls B. Ultrasound-guided regional anaesthesia. Contin Educ Anaesth Crit Care Pain 2007;7:20-4.

11. Sahin T, Balaban O, Sahin L, Solak M, Toke K. A randomized controlled trial of preinsertion ultrasound guidance for spinal anaesthesia in pregnancy: outcomes among obese and lean parturients: ultrasound for spinal anesthesia in pregnancy. J Anesth 2014;28:413-9.

12. Turnbull DK, Shepherd DB. Post-dural puncture headache: pathogenesis, prevention and treatment. Br J Anaesth 2003;91:718-29. 